\title{
Peridotitic diamond formation at Panda (Slave craton, Canada) from paleo-subduction wedge- or mantle-derived fluids ? The bearing of stable isotope data $\left({ }^{15} \mathrm{~N} /{ }^{14} \mathrm{~N},{ }^{33} \mathrm{~S} /{ }^{32} \mathrm{~S},{ }^{34} \mathrm{~S} /{ }^{32} \mathrm{~S},{ }^{13} \mathrm{C} /{ }^{12} \mathrm{C}\right)$.
}

\author{
P. Cartigny ${ }^{1}$, J. Farquhar ${ }^{2}$, J.W. Harris ${ }^{3}$, B. Wing ${ }^{2,4}$, \\ A. Masterson ${ }^{2}$, K. McKeegan ${ }^{5}$, T.S. Stachel ${ }^{6}$
}

1 Laboratoire de Géochimie des Isotopes Stables de l'Institut de Physique du Globe, UMR CNRS 7154, France

2 Earth System Science Interdisciplinary Center and Department of Geology, University of Maryland, College Park MD 20742 USA

3 Department of Geographical and Earth Sciences, University of Glasgow, UK

4 Earth and Space Sciences, UCLA, Los Angeles, CA 90095-1567 USA

5 Department of Earth and Planetary Sciences and GEOTOP-UQAM-McGill, McGill-University, Canada

6 Department of Earth and Atmospheric Science, University of Alberta, Edmonton, AB T6G 2E3, Canada

\section{Introduction}

The mining of diamondiferous kimberlites in Canda, in particular within the Slave craton offers a new opportunuity to test or precise the models of continental lithosphere formation and evolution inferred mostly from the study of the southern african craton. At present diamond mining and thus detailed xenolith and diamond sampling is restricted to kimberlites from Slave, including Northern Slave (Jericho), Central Slave (Ekati, DO-27, Diavik) and southern Canada (Snap Lake).

Among the several first order observations, the age of some eclogite xenoliths appears younger (some extending in the Phanerozoic, Heaman et al., 2007) than that measured among siberian and south-african rocks (Archean in age) and might point to extended rather than early and protracted - lithospheric mantle formation. Furthermore, a first comparison of major element compositions of peridotitic diamonds from south-african and Slave craton suggest the former to be more depleted (Stachel et al., 2003).

The present sudy concentrates on the stable isotope characteristics of diamonds from the Panda kimberlite and aims in better understanding the origin and formation of diamonds at this locality, in particular as to whether fluids derived from a paleo-subduction wedge are required in peridotitic diamond formation as inferred by Westerlund et al (2006) from the Re-Os systematics of sulfide-bearing peridotitic diamonds.

\section{Geological Background and Studied Diamonds}

The Panda kimberlite belongs to the Ekati kimberlite cluster (which also include Koala, Koala North and Misery) and emplaced 53.2 \pm 0.3 Mya (Creaser et al., 2004) within the Central Slave craton.

All the diamonds studied here were previously characterised and discussed by Tappert et al. (2005) and Stachel et al. (2003) for physical characteristics (size, shape, color, plastic deformation), inclusion type and chemistry, infrared-characteristics (N-content and aggregation) and $\delta^{13} \mathrm{C}$ although for the later parameter data were not reported.

On the basis of the inclusion studies, Panda kimberlite yields a large majority of peridotitic diamonds $(n=85)$ fewer eclogitic $(\mathrm{n}=8)$ and lower mantle diamonds $(\mathrm{n}=$ 4) and 3 unknown. Sulfide bearing diamonds are abundant $(\mathrm{n}=17)$ most belonging to the peridotitic paragenesis (15 of 17).

\section{Analytical Techniques}

From the fragments left after diamond breakage, a diamond chip was selected and characterised by microinfrared spectroscopy $(\mathrm{n}=90)$. Detection limits and errors strongly depend on the quality of the cleavage 
chip, but typically range between 10- 20 ppm and about $10-20 \%$ of the concentration respectively.

Samples were subsequently analysed for C- and Nstable isotopes, $\mathrm{N}$-contents after diamond combustion. These analyses follow the experimental procedure given by e.g. Cartigny et al. (2004) with accuracies of $0.5 \%$, $5 \%$ and $0.1 \%$ (all $2 \sigma$ ) for $\delta^{15} \mathrm{~N}, \mathrm{~N}$-contents and $\delta^{13} \mathrm{C}$ respectively.

The sulfur isotope compositions of individual inclusions were measured by secondary ion mass spectrometry with the UCLA Cameca IMS 1270 ion microprobe. Multiple Faraday cup detectors were used for simultaneous measurement of ${ }^{32} \mathrm{~S}^{-},{ }^{33} \mathrm{~S}^{-}$, and ${ }^{34} \mathrm{~S}^{-}$ ion beams following recently established techniques described in Farquhar et al. (2002). Two sigma uncertainties for single $\Delta^{33} \mathrm{~S}( \pm 0.12 \%)$ and $\delta^{34} \mathrm{~S}( \pm 1.4$ \%o) spot analyses have been estimated from the external reproducibility of measurements of the working standard (CAR 123 pyrite) made in all analytical sessions.

\section{Results}

The 75 peridotitic diamonds have a mean $\delta^{13} \mathrm{C}$-value of $-5.2 \%$ and range from -6.9 to $-3.0 \%$, with one single extreme value at $-14.1 \%$ (Fig. 1). Their associated $\delta^{15} \mathrm{~N}$-values range from -17.0 to $+8.5 \%$ with a mean value of $-4.0 \%$. N-contents range from 0 to $1280 \mathrm{ppm}$. The eight eclogitic diamonds have $\delta^{13} \mathrm{C}$ values ranging from -11.2 to $-4.4 \%$ with one single extreme value at $-19.4 \%$. Their $\delta^{15} \mathrm{~N}$ range from -2.1 to $+7.9 \%$ and $\mathrm{N}$-contents are from 0 to $3452 \mathrm{ppm}$. Four diamonds from lower mantle are all Type II (nitrogen-free) and have a narrow $\delta^{13} \mathrm{C}$ interval between -4.5 and $-3.5 \%$, such values being typical of similar diamonds from other localities.

Preliminary data for nine sulphide inclusions in these diamonds shows a narrow range of $\delta^{34} \mathrm{~S}$ with an average of $2.5 \%$ and a range from 0.8 to $6.1 \%$ (normalized to CDT - but without matrix corrections applied for sulphide composition). The $\Delta^{33} \mathrm{~S}$ for these inclusions yield an average value of $0.02 \%$ and a range from -0.32 to $0.20 \%$. These values are within error of juvenile sulphur.

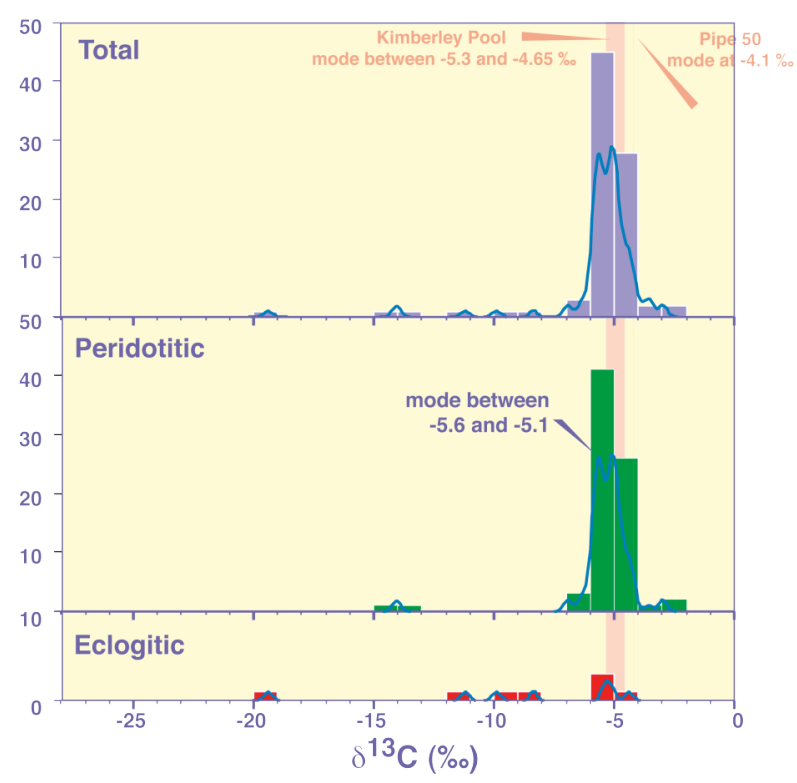

Fig. 1 C-isotope distribution of Panda diamonds

\section{Discussion}

For the two main parageneses, the modes of the $\delta^{13} \mathrm{C}$ distributions are strikingly similar to diamond suites from Yakutian and South-African kimberlites (e.g. Cartigny, 2005). Whilst the $\mathrm{N}$-isotopes in such diamonds are limited geographically to the SinoKorean and South-African cratons, the $\delta^{15} \mathrm{~N}$-range and mean value in the present data from the Slave craton, emphasises the ${ }^{15} \mathrm{~N}$ depleted character of the Earth's sublithospheric mantle relative to external reservoirs (atmosphere, crust, sediments). These very evident similarities between $\delta^{13} \mathrm{C}, \delta^{15} \mathrm{~N}$ and $\mathrm{N}$-content further supports the idea that eclogitic and peridotitic diamonds derive from a common source and that two distinct sources are unlikely (Fig. 1).

The fact that $\delta^{15} \mathrm{~N}$-values are overall negative (average for peridotitic is $-4 \%$ ) demonstrate that the fluids cannot be subduction related which would otherwise yield strictly postive $\delta^{15} \mathrm{~N}$ as recorded within sediments and metamorphic diamonds.

The evidence that Panda peridotitic diamonds formed from mantle-derived fluids is supported by the multiple-S isotope data obtained on sulfide-bearing 
diamonds. Significant deviations from the terrestrial fractionation line (TFL) are known to occur within Archean metasediments (e.g. Farquhar and Wing, 2003). The only known process to produce significant deviation from TFL requires the UV-photolysis of gaseous sulfur-bearing molecule(s) in an anoxic atmosphere and their record among eclogitic diamond inclusion is a further evidence for some eclogite to be subduction-related (Farquhar et al., 2002). The absence of significant deviation form TFL within Panda peridotitic sulfide inclusions thus do not require any involvement of subducted metasedimentary sulfur. This view is supported by the evidence that sulfidebearing diamonds specifically are characterised by strictely negative $\delta^{15} \mathrm{~N}$.

The present isotope data, show that the Slave craton has characteristics similar to those from other cratons and that the formation of diamonds is clearly related to mantle-derived fluids/melts. Such a conclusion is in disagreement with the sugestion of Westerlund et al. (2006) that harzburgitic diamonds from Panda would form from subduction-related fluids. According to such a model, lower, positive and more variable $\delta^{13} \mathrm{C}, \delta^{15} \mathrm{~N}$ and $\Delta^{33} \mathrm{~S}$ respectively would have been expected.

In this respect, the one eclogitic diamond displaying a low $\delta^{13} \mathrm{C}$-value and high $\mathrm{N}$-content cannot be explained by the "fractionation processes" suggested previously. Diamonds with these rare characteristics have been reported recently for a few diamonds from Guinea, Namibia and Botswana and these are within the very few $(\sim 2 / 1000)$ samples that could be subduction-related.

\section{References}

Cartigny, P., 2005. Stable isotopes and the origin of diamond. Elements, 1(2): 79-84.

Cartigny, P., Stachel, T., Harris, J.W. and Javoy, M., 2004. Constraining diamond metasomatic growth using $\mathrm{C}$ - and N-stable isotopes: examples from Namibia. Lithos, 77(1-4): 359373.

Creaser, R.A., Grutter, H., Carlson, J. and Crawford, B., 2004. Macrocrystal phlogopite Rb-Sr dates for the Ekati property kimberlites, Slave Province, Canada: evidence for multiple intrusive episodes in the Paleocene and Eocene. Lithos, 76(1-4): 399-414.

Farquhar, J. and Wing, B.A., 2003. Multiple sulfur isotopes and the evolution of the atmosphere. Earth and Planetary Science Letters, 213(1-2): $1-13$.

Farquhar, J. et al., 2002. Mass-independent sulfur of inclusions in diamond and sulfur recycling on early earth. Science, 298(5602): 2369-2372.

Stachel, T., Harris, J.W., Tappert, R. and Brey, G.P., 2003. Peridotitic diamonds from the Slave and the Kaapvaal cratons - similarities and differences based on a preliminary data set. Lithos, 71(2-4): 489-503.

Tappert, R., Stachel, T., Harris, J.W., Shimizu, N. and Brey, G.P., 2005. Mineral inclusions in diamonds from the Panda kimberlite, Slave Province, Canada. European Journal of Mineralogy, 17(3): 423-440.

Westerlund, K.J. et al., 2006. A subduction wedge origin for Paleoarchean peridotitic diamonds and harzburgites from the Panda kimberlite, Slave craton: evidence from Re-Os isotope systematics. Contributions to Mineralogy and Petrology, 152(3): 275-294. 